\section{International Scientific Journal Theoretical \& Applied Science}

\author{
p-ISSN: 2308-4944 (print) e-ISSN: 2409-0085 (online) \\ Year: $2016 \quad$ Issue: 12 Volume: 44
}

Published: $12.12 .2016 \quad \underline{\text { http://T-Science.org }}$

SECTION 20. Medicine.
Zanna Robertovna Gardanova

Professor, doctor of medical sciences, head of the

Department of psychotherapy,

Pirogov Russian National Research Medical University, Moscow, Russia zanna7777@inbox.ru

Vladimir Igorevich Esaulov Institute of psychotherapy and clinical psychology Psychotherapy Department, Lecturer, Assistant, Department of Psychotherapy, Pirogov Russian National Research Medical University, Moscow, Russia v-esaulov@yandex.ru

Yulia Igorevna Kekteeva Assistant, Department of Psychotherapy, Pirogov Russian National Research Medical University,

Moscow, Russia ulechka87-87@mail.ru

\title{
SHORT-TERM PREVENTION AND CORRECTION OF PSYCHOEMOTIONAL DISORDERS AMONG OBSTETRICIAN- GYNAECOLOGISTS BECAUSE OF EMOTIONAL BURNOUT SYNDROME
}

\begin{abstract}
: 30 obstetrician-gynaecologists were examined in order to find out symptoms of emotional burnout syndrome (EBS). With the help of the clinical interview, the questionnaire and psycho diagnostic tests the initial observation was held. More than 50 per cent of observed doctors had symptoms of somatic manifestations of EBS and also they had high-level of anxiety and sub-depression. After the survey and tests all 30 doctors were offered two sessions with a psychologist (with an opportunity to continue the treatment if needed). 17 out of 30 people agreed to attend those sessions where they were taught how to use relaxation techniques and they were given help in the research and solutions of various psychological problems. The results of the research could be useful to prevent EBS and for other psychocorrection work in case of EBS development among obstetrician-gynecologists.

Key words: Obstetrician-gynecologists, professional stress, psychodiagnostic tests, emotional burnout syndrome, anxiety, depression, prevention, psychocorrection.

Language: Russian

Citation: Gardanova ZR, Esaulov VI, Kekteeva YI (2016) SHORT-TERM PREVENTION AND CORRECTION OF PSYCHOEMOTIONAL DISORDERS AMONG OBSTETRICIAN-GYNAECOLOGISTS BECAUSE OF EMOTIONAL BURNOUT SYNDROME. ISJ Theoretical \& Applied Science, 12 (44): 19-23.

Soi: http://s-o-i.org/1.1/TAS-12-44-4 Doi: crossef http://dx.doi.org/10.15863/TAS.2016.12.44.4

\section{КРАТКОСРОЧНАЯ ПРОФИЛАКТИКА И КОРРЕКЦИЯ ПСИХОЭМОЦИОНАЛЬНЫХ РАССТРОЙСТВ ПРИ РАЗВИТИИ СИНДРОМА ЭМОЦИОНАЛЬНОГО ВЫГОРАНИЯ У ВРАЧЕЙ АКУШЕРОВ-ГИНЕКОЛОГОВ}

Аннотация: Обследовано 30 врачей акушеров-гинекологов с иелью диагностики у них проявлений синдрома эмоционального выгорания (СЭВ). Первичное обследование проводилось с помощью клинического интервью, анкетирования, и психодиагностических тестов. Более чем у половины обследованных выявлены соматические проявления СЭВ, в сочетании с повышенными показателями личностной и реактивной тревожности, субдепрессией. После опроса и тестирования всем 30 человекам были предложень две сессии с психологом (с возможностью при желании их продолжения). Предлагалась помощь в исследовании и решении различных психологических проблем, а также обучение релаксационным приемам. 17 из 30 чел. согласились и посетили эти занятия. Полученные результаты диагностики и краткосрочной психокоррекции могут быть полезны для профилактики СЭВ и психокорекционных мероприятий при развитии эмоционального выгорания у акушеров-гинекологов.
\end{abstract}


Ключевые слова: врачи акушеры-гинекологи, профессиональный стресс, эмоциональное выгорание, психодиагностические тесты, тревожность, депрессия, профилактика, психокоррекция.

\section{Введение}

Врачебная деятельность сопровождается, как правило, интенсивной рабочей нагрузкой, высокой насыщенностью профессиональных контактов с самыми разными людьми. Среди тех, с кем приходится общаться врачам различных специальностей, встречаются люди с самыми разными темпераментами, личностными особенностями, по-разному переживающих проблемы со здоровьем. Нередко среди них встречаются пациенты со сложным характером, трудные в общении, требовательные, капризные, порой изначально настороженно относящиеся к медицинскому персоналу и мед.обследованиям.

Многолетняя работа врача в условиях интенсивных контактов, повышенной требовательности к информационнокоммуникативной сфере врачебной работы на фоне хронической рабочей перегрузки без права на ошибки, необходимости постоянно быть на пике высоких профессиональных стандартов и максимально включаться в общение с каждым из пациентов, может привести в ряде случаев к явлениями профессиональной деформации, эмоциональному выгоранию [1-4].

При этом у некоторых врачей наблюдается потеря заинтересованности в работе, появление формального отношения к своим профессиональным обязанностям, ощущение «измотанности» и эмоционального истощения, снижение профессиональной самооценки [1-4].

Все вышеописанные явления обычно можно наблюдать либо спустя короткое время работы по выбранной специальности, когда наступает первичное разочарование и потеря интереса, либо - по мере увеличения рабочего стажа по специальности, когда возникает «профессиональная усталость». Особенно выраженными явления эмоционального выгорания бывают при работе с пациентами, имеющими проблемное психоэмоциональное состояние (с наличием неврозо- и психопатоподобных расстройств), сочетающимся c выполнением интенсивно-однообразной работы, при сложной межличностной рабочей атмосфере в коллективе, работой в условиях повышенной профессиональной конкуренции, при эмоциональной и материальной недооценке рабочего вклада, а также ненормированном рабочем дне [1-6].

Зачастую именно такие условия работы и такую рабочую нагрузку можно наблюдать у врачей акушеров-гинекологов [6]. Специфика работы этой категории врачей, и возможность развития явлений эмоционального выгорания ранее уже была описана нами в предыдущей работе [7].

В то же время, с нашей точки зрения, недостаточно полно изучена возможность профилактики и краткосрочной психокоррекции при развитии синдрома эмоционального выгорания у врачей акушеров-гинекологов.

Целью работы является исследование возможностей профилактики и готовности работы с психологом (психотерапевтом) в режиме краткосрочной психокоррекции при развитии синдрома эмоционального выгорания у врачей акушеров-гинекологов.

Материалы и методы: обследовано 30 врачей акушеров-гинекологов, работающих в мед.учреждениях г.Москвы. Со всеми 30 врачами проведено интервьюирование, и обследование набором психологических тестов (MBI, Тест Бека, Тест Спилбергера-Ханина).

Первичное интервью и анкетирование длилось в течение получаса, затем обследуемым предлагалось заполнение психодиагностических тестов.

После прохождения тестирования и обработки данных предлагались два занятия с психологом/психотерапевтом, направленные на работу с выявленными психологическими проблемами обследованных (при их наличии), либо - на профилактику СЭВ. Две сессии с психологом/психотерапевтом проводились в режиме примерно 1-1,5 часовых занятий раз в 5-7 дней. За основу психокоррекционных занятий был взят интегративный психотерапевтический подход.

\section{Результаты и обсуждение}

В проведенном нами исследовании основное внимание направлялось на изучение специфики эмоциональных проявлений выгорания, частности - исследованию интенсивности тревожно-депрессивных расстройств, а также прояснению степени заинтересованности обследованных на коррекцию этих расстройств в режиме краткосрочных занятий.

Полученные при опросе и анкетировании сведения подтвердили наличие более чем у половины обследованных (21 чел.) типичных для синдрома эмоционального выгорания психоэмоциональных расстройств и соматических симптомов. Испытуемые в основном предъявляли жалобы астеносубдепрессивного (истощение, тоскливость) и тревожного (волнение, тревога, внутренний

ISPC Generalization of scientific results, 
дискомфорт) характера. Среди наиболее часто встречающихся расстройств отмечались: тревога (17 чел.), пониженное настроение (14 чел.), раздражительность (14 чел.), потеря интереса и безразличие к работе (17 чел.), хроническая усталость на работе (15 чел.).

Нарастание указанных проявлений наблюдалась при увеличении рабочего стажа, и достигало пика примерно к сорока годам при продолжительности работы более 10 лет. В старшей возрастной группе указанные явления несколько уменьшались по частоте встречаемости.

Тестирование опросником MBI также позволило более чем у половины обследованных врачей выявить повышенные показатели уровня «эмоционального истощения», проявляющегося чувством эмоциональной опустошенности и усталости, связанного с работой.

Тестирование опросником А.Бека показало отсутствие депрессии у 12 человек. У остальных 18 обследованных выявлены показатели, характерные для субдепрессии (14 чел.) и депрессии.

Результаты тестирования опросником Спилбергера-Ханина указали на преобладание у обследованных среднего и повышенного уровней личностной и реактивной тревожности. В целом эти данные близки к результатам обследования врачей акушеров-гинекологов, проведенного в 2005 году Д.А. Марченко-Тябут и А.А. Головач [6].

Интересной была реакция на саму процедуру опроса и тестирования части обследованных врачей. 4 чел. $(13,3 \%)$ не проявили интереса к результатам диагностики, односложно отвечали на вопросы, и отказались от повторной встречи, заявив, что им в целом безраличны полученные результаты, и они согласились на тестирования «просто из уважения к коллегам», или по просьбе начальства.

Как уже отмечалось выше, всем 30 обследованным после тестирования и опроса были предложены две индивидуальные психокоррекционные сессии с психологом /психотерапевтом вне зависимости от полученных показателей психоэмоционального состояния. Участникам проводимого обследования в режиме анонимности предлагалась помощь в исследовании и решении различного рода психологических проблем, а также при желании - обучение релаксационным приемам снятия напряжения. Предусматривалась и более долгосрочная работа с психологом в случае высказанного участниками исследования желания продолжить общение на интересующие обследованных темы.
При этом 13 человек (43,3 \%) из 30 отказались от предложенных занятий с психологом по различным причинам. Мотивами отказа являлись:

$\square$ отрицание каких-либо проблем в соматической и психоэмоциональной сферах (7 чел. $-23,3 \%)$;

$\square$ недостаток времени на предложенные занятия (2 чел.-6,7\%);

$\square$ "нежелание обсуждать свою жизнь" с психологом / "...и вообще - с кем-то еще" (2 чел.$6,7 \%)$

$\square$ отсутствие интереса к предложенным занятиям (2 чел.- 6,7\%).

Среди тех. кто отказался от предложенных занятий, почти половину (6 чел.) составляли те обследованные, у которых при опросе и анкетировании были выявлены признаки СЭВ. Большая часть из этих "отказников" (4 из 6 чел.) приходилась на возраст свыше 50 лет, и имела весьма продолжительный стаж работы по специальности.

Следует отметить, что наибольший интерес к занятиям проявили молодые врачи, имеющие непродолжительный стаж работы, и с невысокими показателями тревожности и депрессии, а также врачи старше 45 лет. имеющие средне-высокие показатели депрессии и тревоги.

Проведенные с 17 обследованными занятия с психологом/психотерапевтом базировались на интегративном психотерапевтическом подходе. В каждом отдельном случае при необходимости использовались психотерапевтические техники, включающие элементы нейро-линвистического программирования, эриксоновский гипноз, арттерапию, позитивную терапию, техники психомышечной релаксации и элементы аутотренинга [4,8-12].

Большая часть сессий содержала краткое описание сути СЭВ, трактовку полученных результатов психодиагностики, рекомендации по расчетливому распределению своих нагрузок, а также необходимости обучения умению переключаться на другой вид деятельности; проведение упражнений по ресурсированию, и, при необходимости, - работу по уменьшению имеющегося напряжения, а также обучение релаксационным приемам индивидуально или в режиме малых групп.

12 из 17 человек, прошедших краткосрочные занятия с психологом, отметили их полезность для себя, и отмечали некоторое общее улучшение самочувствия, субъективное снижение ситуативной тревожности, более спокойное отношение к стрессовым рабочим ситуациям.

8 из 17 проявили интерес к периодическим дальнейшим занятиям, заметив, что занятия помогли им "больше вспомнить о себе", 
необходимости разрешить себе больше отдыхать. 4 чел.из этой группы попросили о продолжении регулярных занятий с психологом для решения собственных психоэмоциональных проблем.

22 человека из 30 обследованных (в это число вошли и те врачи, которые сами отказались от занятий с психологом/психотерапевтом) отметили, что режим регулярных краткосрочных занятий было бы полезно ввести в первую очередь не столько для врачей, сколько для их пациентов, По высказанному ими мнению, постоянная работа психолога/психотерапевта с их пациентами и родственниками позволила бы облегчить рабочую нагрузку, снижала бы напряжение, и могла бы способствовать более продуктивному общению и эффективной работе с весьма непростой и эмоциональнотребовательной категорией пациенток.

\section{Заключение}

Успешная профилактика возникновения синдрома эмоционального выгорания у врачей различных специальностей может базироваться в первую очередь на понимании специфики медицинской работы, связанной с высокой психоэмоциональной и коммуникативной нагрузкой. Кроме того, необходима своевременная диагностика начальных проявлений эмоционального выгорания. При появлении психоэмоциональных нарушений, типичных для СЭВ, целесообразно оказание психолого-психотерапевтической помощи, направленной на купирование имеющейся симптоматики, возникающей вследствие рабочих перегрузок и профессиональных стрессов. В полной мере это имеет отношение и к обследованной группе врачей-гинекологов.

В качестве одного из составляющих элементов успеха может быть налаживание регулярного взаимодействия и сотрудничества между администрациями мед.учреждений, где работает мед.персонал, и различных психологических центров и кафедр, имеющих квалифицированных психологов и психотерапевтов, обладающих необходимым опытом и навыками работы с СЭВ.

Целесообразным, по нашему мнению, является введение периодического тестирования персонала мед.учреждений с целью выявления признаков СЭВ, проведение курса образовательных и разгрузочных занятий, направленных на профилактику этого вида профессиональной патологии и профессиональной деформации личности, Эти занятия могут быть дополнены обучением медиков специальным релаксационным и ресурсным приемам, позволяющим снизить профессиональную эмоциональную и коммуникативную перегрузку.

Полученные в ходе данного исследования результаты могут быть полезны при разработке психокоррекционных мероприятий в случаях развития эмоционального выгорания у акушеровгинекологов.

\section{References:}

1. Balakhonov AV, Belov VG, Pyatibrat ED, Pyatibrat AO (2009) Emotsional'noe vygoranie u meditsinskikh rabotnikov kak predposylka astenizatsii i psikhosomaticheskoi patologii // Vestnik Sankt-Peterburgskogo universiteta 2009. T.11, № 3. - p. 57-71.

2. Sidorov PI (2005) Sindrom ehmocional'nogo vygoraniya // Medicinskaya gazeta. №43 (8.06.2005); Available: http://www.medgazeta.rusmedserv.com/2005/4 3/article 322.html (Accessed: 11.11.2016).

3. Kajbyshev VT (2006) Professional'no determinirovannyj obraz zhizni i zdorov'e vrachej v usloviyah sovremennoj Rossii // Medicina truda i prom. ehkologiya. - 2006. № 12. - p. 21-26.

4. Vodop'yanova NE, Starchenkova ES (2011) Sindrom vygoraniya: diagnostika i profilaktika. - 2-e izd. - SPb.: Piter, 2011. - 223 p.
5. Nikolaev EL (2015) Chto volnuet medicinskogo rabotnika na rabochem meste: psihologicheskij kontekst profilaktiki professional'nogo stressa //Vestnik psihiatrii i psihologii Chuvashii -2015. T.11, № 3. - p. 2745.

6. Marchenko-Tyabut DA, Golovach AA (2005) Lichnostnaya i reaktivnaya trevozhnost' u vrachej razlichnyh special'nostej // Medicina. 2005. №2. - p. 79 - 81.

7. Gardanova ZR, Esaulov VI, Kekteeva YuI. (2016) Osobennosti ehmocional'no-lichnostnoj sfery pri razvitii sindroma ehmocional'nogo vygoraniya u vrachej akusherov-ginekologov // Sovremennye problemy nauki i obrazovaniya. 2016. - № 6.; Available: http://www.scienceeducation.ru/ru/article/view?id=25477 (Accessed: 11.11.2016). 


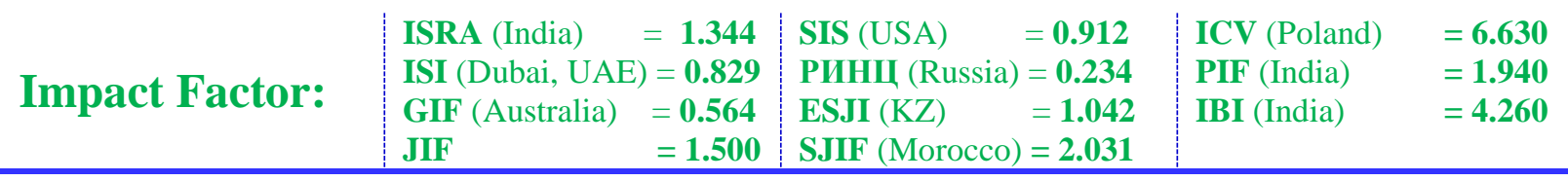

8. Filatov AS (1979) Autogennaya trenirovka. Kiev, Zdorov'ya. -1979. - 144 p.

9. Ahola T, Furman B (2000). Kratkosrochnaya pozitivnaya psihoterapiya - SPb.: Izd-vo Rech'2000. -220 p.

10. Kovalev SV (2006) Iscelenie s pomoshch'yu NLP. M.: Izd-vo: KSP+. -2006. - 542 p.
11. Gordeev MN (2005) Gipnoz: Prakticheskoe rukovodstvo. 3-e izd.- M.; Izd-vo Instituta Psihoterapii, 2005. - 240 p.

12. Gordeev MN, Gordeeva EG (2008). NLP v psihoterapii. M.; Izd-vo:Psihoterapiya. -2008. $272 \mathrm{p}$. 